\title{
IRREGULAR FLAT SLABS DESIGNED ACCORDING TO STRUCTURAL MEMBRANE APPROACH
}

\author{
K. BASKARAN
}

Department of Civil Engineering, University of Moratuwa, Sri Lanka

Keywords: flat slab, membrane, bimoment.

\section{INTRODUCTION}

Flat slabs are less labour intensive, simplify the installation of services and can accommodate more floors within restricted heights. However, the span influencing their design is the longest and they require more steel compared to two-way slabs. Other drawbacks of flat slabs are vulnerability to punching shear failure and higher deflections. To avoid punching shear failure drop panels, column heads or shear reinforcement are used. If span in flat slabs is reduced then both deflection and punching shear problems can be avoided. However, architects prefer to have few exposed columns in usable areas. This inevitably leads to columns in an irregular layout, hidden inside partitions or walls [1]. Flat slab construction with columns in an irregular layout is a viable solution in constructing buildings that satisfy their functional requirements in urban environments.

The purpose of this paper is three fold. One is to encourage the application of the structural membrane approach to design flat slabs on non-rectangular column grid by providing experimental evidence $[2,3]$. Second is to encourage more research on bimoment concepts. Third is to leave some carefully performed experimental evidence for the research community to be used in validating structural assessment tools like nonlinear finite element or yield line analysis. In the next section, existing approaches to design flat slabs on non-rectangular column layout are briefly reviewed. Methods involving trial and error, like yield line design (considering the slab with an assumed steel distribution and assessing the load capacity for possible yield line patterns) or elastic finite element analysis (which results in peaky moments above columns and needs experience to perform redistribution) are not considered. This is followed by a simplified introduction to structural membrane approach applied to flat slabs. When applied to flat slabs, twisting moments along particular directions are assumed negligible in the structural membrane approach. This assumption is checked by using Gurley's bimoment concepts applied to flat slabs on square column layout [4]. In the following sections experimental method, details of specimens and their behaviour at ultimate load and service load are discussed before concluding the paper.

\section{STATE OF THE ART}

To the author's knowledge, despite the long history of flat slab construction, design methods for flat slabs supported on non-rectangular column layouts were attempted only from the early seventies (Van Buren [5], Wiesinger [1]). Wiesinger proposed to divide the panel into triangular grid and calculate column and middle strip moments considering the equilibrium of loads transferred by each strips. One problem with Wiesinger's approach is the assumption that lines connecting panel centres with columns as zero shear lines but the method hasn't got any moment calculations along those lines. Instead it calculates the moments considering them as concentrated moments, and distributed them according to $\mathrm{ACl}$ direct design method. Further, one can argue, do we always need to limit the division of slab panels to triangles? Why not quadrilaterals, pentagons etc? In the following subsections design methods for flat slabs on any layout of columns and brief details of irregular flat slabs tested at NTU (Nanyang Technological University) are given.

Building failures in case of extreme overload can be classified into two groups: ductile failures and brittle failures. Ductile failures involve extensive concrete cracking, and considerable deflections, which give warning to the people about the distress of the building and allow them to evacuate the building. As concrete is a brittle material, yielding of steel before failure is the key for ductile failures and achieved only with lightly reinforced slabs. To ensure slabs are reinforced to have ductile failures, design codes generally specify the maximum steel ratio. Also ductile structures allow the designers to select a steel layout, which can be constructed with ease. 


\subsection{Design methods based on "safe" lower bound theorem}

The lower bound theorem requires equilibrium of forces, everywhere in the structure, without violating yield criterion anywhere in the structure for the structure (ductile) to be safe. The equilibrium equation for a slab is of the form

$$
\frac{\partial^{2} M_{x}}{\partial x^{2}}+2 \frac{\partial^{2} M_{x y}}{\partial x \partial y}+\frac{\partial^{2} M_{y}}{\partial y^{2}}=-p
$$

Hillerborg pointed out that, according to the lower bound theorem any combination of $M_{X}, M_{x y}$, and $M_{y}$, satisfying above equation with suitable reinforcements to carry these loads leads to a safe structure [6]. Also, torsional stiffness degrades drastically with cracking. Therefore he neglected the twisting moment resistance and distributed the loading between the reinforcements along strips in the $x$, and $y$ directions. For a two-way slab supported on beams these strips carry the load to the beams. However, in flat slabs there are no beams. Therefore column strips have to support middle strips and columns in turn support the column strips.

One approach to tackle flat slabs on irregular column layout is to consider strong bands along column lines [7]. These strong bands function as beams hidden inside slab panels. Loads applied on panels are first transferred to strong bands and strong bands in turn carry them to columns. Kemp pointed out two weaknesses with the strong band approach: decision on the width of the strong band is left with the designer and strength available in significant portions of slab panels is not utilised [8].

Hillerborg [9] proposed the following steps to design flat slabs on irregular column layout:

- Decide suitable reinforcement directions for an orthogonal steel layout.

- Determine the theoretical column profiles by drawing inscribed rectangles with edges parallel to reinforcement directions.

- Determine the location of zero shear force lines and draw the support lines (strong bands) along the edges of the theoretical column profile parallel to reinforcement directions up to zero shear force lines.

- Calculate the total moment for each support line and choose support moments and calculate span moments. Based on the values of the span moments, for a span from adjacent regions, modify the location of zero shear lines and repeat the moment calculation step until the difference between the span moments is acceptable.

- Provide reinforcement according to the calculated moments after performing moment distribution.

Although this method provides general design rules and simple reinforcement layout, it doesn't assure that the reinforcement layouts are along the principal moment directions suggested by linear elastic analysis. Therefore it can lead to poor reinforcement economy and considerable cracking [9].

\subsection{What is Structural membrane approach?}

Recently Saether proposed a design method based on equilibrium along strip directions $[2,3]$. His method divides the panel into regions consisting of three basic building blocks from shallow shell theory: domes, paraboloids, and funnels. The moment in the slabs corresponds to the membrane thrust in the shell multiplied by the vertical eccentricity of the shell surface from a reference plane. Thus a dome corresponds to a sagging moment in both directions; a paraboloid to sagging in one direction and hogging in the other; and a funnel to a complex hogging region. Following equilibrium along the principal shell curvature directions corresponds to neglecting twisting moments in the slab. The procedure to identify the locations of these building blocks and the following calculations to find moment values are discussed in detail by Saether $[2,3]$.

To compare the Hillerborg's suggestion with Saether's approach, consider a flat slab supported on parallelogram column layout. The locations of zero shear force lines are same in both methods. However, the way in which the middle strips are supported is different. The orthogonal strong bands 
(cantilevers) support the middle strips in Hillerborg's suggestion whereas column strips along column lines support them in Saether's approach (see Fig.1 below). Further, in Saether's method relative rotations along the strips are minimized by applying corrections to moments calculated along middle and column strips [2]. This effectively narrows the range of equilibrium solution by appealing to elastic compatibility consideration - something that Hillerborg does not explicitly do, though he suggests not departing far from the linear elastic solution. This author prefers Saether's continuous column strip supporting middle strips compared to Hillerborg's cantilever strong bands because all Sather's column strips have sagging moments near mid span, in contrast to Hillerborg's cantilever.

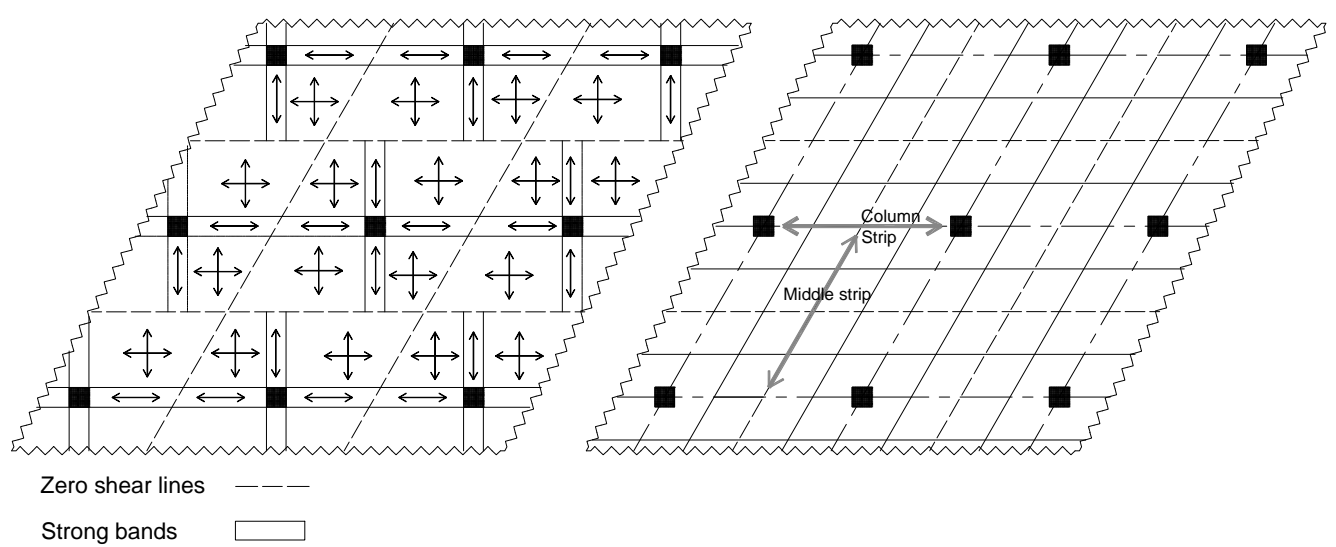

(a) Hillerborg's suggestion

(b) Saether's method

Fig. 1 Flat slab supported on parallelogram column layout-panel division

\subsection{How valid is the zero twisting moment assumption?}

In Saether's method or Hillerborg's approach twisting moments are neglected. But if an estimate of twisting moments is made then it can be included in the design following Wood-Armer equations [13]. Gurley proposed bimoment concept to design slabs, neglecting torsional resistance [4]. The key to the bimoment method is the hyperbolic paraboloid shaped displacement field as stated by Lowe [14]. Bimoments (moment of moments) are moments about two orthogonal lines passing through a point. Gurley suggested that in the absence of twisting moments, over turning bimoments and restoring bimoments are equal. In this paper, scenarios with non-zero twisting moment are considered to see what changes it makes to the bimoment equations, and any useful conclusions can be drawn. Known equilibrium systems for simply supported and beamless column supported square slabs are first considered. The observations made from them are used in interior panels on square column grid that are designed following Hillerborg's suggestion [9] and Saether's method [2,3].

\subsubsection{Simply supported square slab}

Consider a simply supported square slab with span $L$ subjected to uniform load $p$ as shown in Fig. $2 \mathrm{a}$. Wood showed the resulting moment distribution, in a possible equilibrium system for the panel, could be given as [15]

$$
M_{x}=\frac{p L^{2}}{24}-\frac{p x^{2}}{6}, M_{y}=\frac{p L^{2}}{24}-\frac{p y^{2}}{6}, M_{x y}=+\frac{p x y}{6} \text { and } V_{x}=\frac{\partial M_{x}}{\partial x}-2 \frac{\partial M_{x y}}{\partial y}
$$

Using symmetry the calculations can be limited only to the shaded portion in Fig. 2a.

$$
\begin{array}{lll}
\text { Along the edge } & x=\frac{L}{2}: & M_{X}=0, M_{x y}=+\frac{p L y}{12}, \text { and } V_{X}=-\frac{p L}{3} \\
\text { Similarly along the edge } \quad y=\frac{L}{2}: & M_{y}=0, \text { and } M_{x y}=+\frac{p L x}{12}
\end{array}
$$




$$
\begin{array}{lll}
\text { Along the section } & x=0: & M_{x}=\frac{p L^{2}}{24}, \text { and } M_{x y}=0 \\
\text { Similarly along } & y=0: & M_{y}=\frac{p L^{2}}{24}, M_{x y}=0
\end{array}
$$

The overturning bimoment about corner $\mathrm{A}=p(L / 2)^{2}(L / 4)(L / 4)=\frac{p L^{4}}{64}$

The resisting bimoment about corner $\mathrm{A}=\frac{p L^{2}}{24} \times \frac{L}{2} \times \frac{L}{4} \times 2=\frac{p L^{4}}{96}$

The difference between bimoments $p L^{4} / 192$ shows the existence of twisting moments.

Consider the virtual displacement field $\delta w=(x-L / 2)(y-L / 2)$

From virtual work, External work done $=$ Internal energy dissipated

External work done $\int_{0}^{L / 2} \int_{0}^{L / 2} p . \delta w \cdot d x . d y+\left.\left.\int_{0}^{L / 2} M_{X}\right|_{x=0} \frac{d \delta w}{d x}\right|_{x=0} d y+\left.\left.\int_{0}^{L / 2} M_{y}\right|_{y=0} \frac{d \delta w}{d y}\right|_{y=0} d x=\frac{p L^{4}}{192}$

Internal energy dissipated $=\int_{A}\left(M_{x} \cdot \kappa_{X}+M_{y} \cdot \kappa_{y}+2 M_{x y} \cdot \kappa_{x y}\right) \cdot d A=\frac{p L^{4}}{192}$

where curvatures $\kappa_{X}=\kappa_{y}=0$ and $\kappa_{x y}=1$.

This result shows that the difference in calculated bimoments is due to the twisting moments inside the shaded region. The average value of twisting moment can be found using

$=\int_{A} 2 M_{x y} \cdot d A=2 \overline{M_{x y}} A=$ difference in bimoments

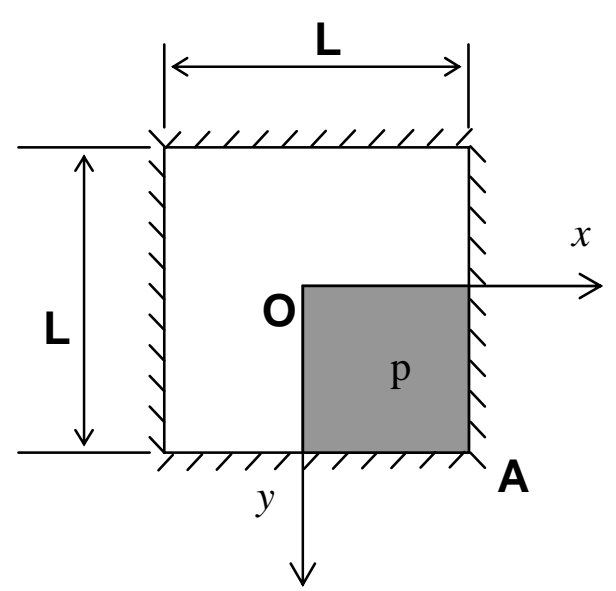

(a) Simply supported

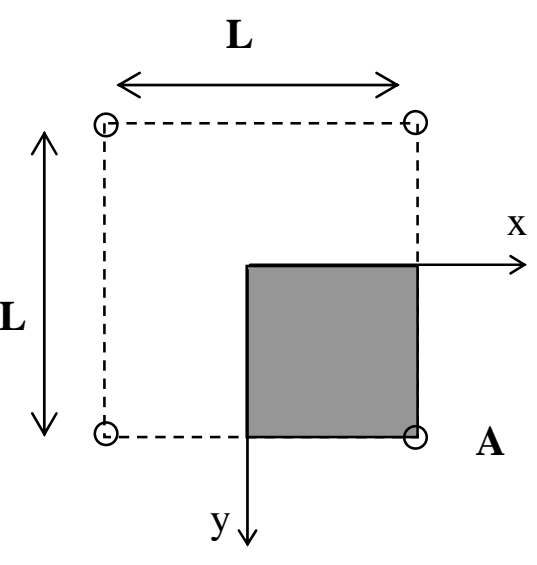

(b) Interior panel of flat slab

Fig. 2 Square slab to study non-zero twisting moment cases 


\subsubsection{Wood and Armer's solution to flat slab}

Wood and Armer proposed the following equilibrium system as an alternative to Hillerborg's advanced strip method [7]. Fig. $2 \mathrm{~b}$ shows the square panel with the shaded quarter panel considered for bimoment calculations.

$$
M_{x}=\frac{p L^{2}}{8}\left(1-\frac{4 x^{2}}{L^{2}}\right)-\frac{K_{1} p L^{2}}{8}, M_{y}=\frac{p L^{2}}{8}\left(1-\frac{4 y^{2}}{L^{2}}\right)-\frac{K_{2} p L^{2}}{8}, M_{x y}=-\frac{p x y}{2}
$$

Calculating overturning and resisting bimoments about corner A (noting that $M_{x y}$ is zero along $x=0$ and $y=0$ )

Overturning bimoment $=p \frac{L^{2}}{4} \cdot \frac{L}{4} \cdot \frac{L}{4}=\frac{p L^{4}}{64}$

Resisting bimoment $=\frac{p L^{2}}{8}\left(1-K_{1}\right) \frac{L}{2} \frac{L}{4}+\frac{p L^{2}}{8}\left(K_{1}\right) \frac{L}{2} \frac{L}{4}+\frac{p L^{2}}{8}\left(1-K_{2}\right) \frac{L}{2} \frac{L}{4}+\frac{p L^{2}}{8}\left(K_{2}\right) \frac{L}{2} \frac{L}{4}=\frac{p L^{4}}{32}$

The difference $\frac{p L^{4}}{64}$ between bimoments shows presence of twisting moments within the quarter panel. Considering the deformed shape as a hyperbolic paraboloid as in the previous section, internal energy dissipated $=\int_{A}\left(M_{x} \cdot \kappa_{X}+M_{y} \cdot \kappa_{y}+2 M_{x y} \cdot \kappa_{x y}\right) d A=\frac{p L^{4}}{64}$

where curvatures $\kappa_{x}=\kappa_{y}=0$ and $\kappa_{x y}=1$.Average twisting moment $\left|\overline{M_{x y}}\right|=\frac{p L^{2}}{32}$.

\subsubsection{Hillerborg and Saether's solutions to flat slabs on square column grid}

In the previous sections two known equilibrium systems were considered. In this section, again interior panel of flat slab on a square column grid is considered. According to Hillerborg's simplified rules for the design [9], a designer can consider the boundaries along the column line as fixed and then the support moment $m_{S}=p L^{2} / 12$

and the corresponding span moments are $m_{f}=p\left(\frac{L}{2}\right)^{2} / 2-p L^{2} / 12=\frac{p L^{2}}{24}$.

Hillerborg suggested various ways to distribute the moments, all satisfying the overall equilibrium equations in the $x, y$ directions [9]. Overturning and resisting bimoments are calculated for some of these moment distributions and the differences, normalised by overturning bimoments are tabulated in Table 1.

For Saether's method, consider an interior panel of square column layout with $0.2 \mathrm{~m}$ diameter columns spaced at $4 \mathrm{~m}$ intervals. Taking advantage of symmetry it is sufficient to analyse quarter of the panel. The calculated moment values are shown in Fig. 3. In the bimoment calculations column reactions are neglected.

Overturning bimoment about column A $=10 \times(4) \times 1 \times 1=40 \mathrm{kNm}^{2}$

Restoring bimoment about column $\mathrm{A}$

$$
2(53 \times 0.1 \times 0.05+20.7 \times 0.9 \times 0.55+2.5 \times 1 \times 1.5+2.5 \times 1 \times 1.5+10.6 \times 1 \times 0.5)=46.6 \mathrm{kNm}^{2}
$$

Therefore the difference in bimoments as a percentage is $16.5 \%$. If this twisting moment is assumed as uniformly distributed in the column strip intersection.

$M_{x y}=\frac{6.6}{2 \times 1}=3.3 \mathrm{kNm}$. This is about $16 \%$ of the average moment in the column region. 
Morley Symposium on Concrete Plasticity and its Application. University of Cambridge $23^{\text {rd July, } 2007}$

Table 1 Bimoment values for various moment distributions suggested by Hillerborg

\begin{tabular}{|c|c|c|c|}
\hline \multicolumn{2}{|c|}{ Moment distribution } & \multirow{2}{*}{$\begin{array}{l}\text { Resisting } \\
\text { bimoment }\end{array}$} & \multirow{2}{*}{$\frac{\text { Bimoment difference }}{\text { Overturning bimoment }\left(p L^{4} / 64\right)} \times 100$} \\
\hline $\mathrm{m}_{\text {support }}$ & $\mathrm{m}_{\text {span }}$ & & \\
\hline $\begin{array}{c}2 \mathrm{~m}_{\mathrm{s}} \text { over } \mathrm{L} / 4, \text { and } 0 \\
\text { over other } \mathrm{L} / 4\end{array}$ & $m_{f}$ over $L / 2$ & $\frac{p L^{4}}{48}$ & 33.3 \\
\hline $\begin{array}{c}1.6 \mathrm{~m}_{\mathrm{s}} \text { over } \mathrm{L} / 4 \text {, and } \\
0.4 \mathrm{~m}_{\mathrm{s}} \text { over other } \\
\mathrm{L} / 4\end{array}$ & $m_{f}$ over $L / 2$ & $\frac{p L^{4}}{40}$ & 60 \\
\hline $\begin{array}{l}3 \mathrm{~m}_{\mathrm{s}} \text { over } \mathrm{L} / 6, \text { and } \\
\text { zero other } \mathrm{L} / 3\end{array}$ & $m_{f}$ over $L / 2$ & $\frac{5 p L^{4}}{288}$ & 11.1 \\
\hline $\begin{array}{c}2 m_{s} \text { over } L / 4 \text {, and } 0 \\
\text { over other } L / 4\end{array}$ & $\begin{array}{c}1.2 \mathrm{~m}_{\mathrm{f}} \text { over } \mathrm{L} / 4 \text { in } \\
\text { column strip, and } \\
0.8 \mathrm{~m}_{\mathrm{f}} \text { over other } \\
\mathrm{L} / 4\end{array}$ & $\frac{19 p L^{4}}{960}$ & 26.7 \\
\hline $\begin{array}{l}1.6 \mathrm{~m}_{\mathrm{s}} \text { over } \mathrm{L} / 4 \text {, and } \\
0.4 \mathrm{~m}_{\mathrm{s}} \text { over other } \\
\mathrm{L} / 4\end{array}$ & $\begin{array}{c}1.2 \mathrm{~m}_{\mathrm{f}} \text { over } \mathrm{L} / 4 \text { in } \\
\text { column strip, and } \\
0.8 \mathrm{~m}_{\mathrm{f}} \text { over other } \\
\mathrm{L} / 4\end{array}$ & $\frac{23 p L^{4}}{960}$ & 53.3 \\
\hline $\begin{array}{l}3 \mathrm{~m}_{\mathrm{s}} \text { over } \mathrm{L} / 6 \text {, and } \\
\text { zero over other } \\
\mathrm{L} / 3\end{array}$ & $\begin{array}{c}1.2 \mathrm{~m}_{\mathrm{f}} \text { over } \mathrm{L} / 4 \text { in } \\
\text { column strip, and } \\
0.8 \mathrm{~m}_{\mathrm{f}} \text { Over other } \\
\mathrm{L} / 4\end{array}$ & $\frac{47 p L^{4}}{2880}$ & 4.44 \\
\hline
\end{tabular}

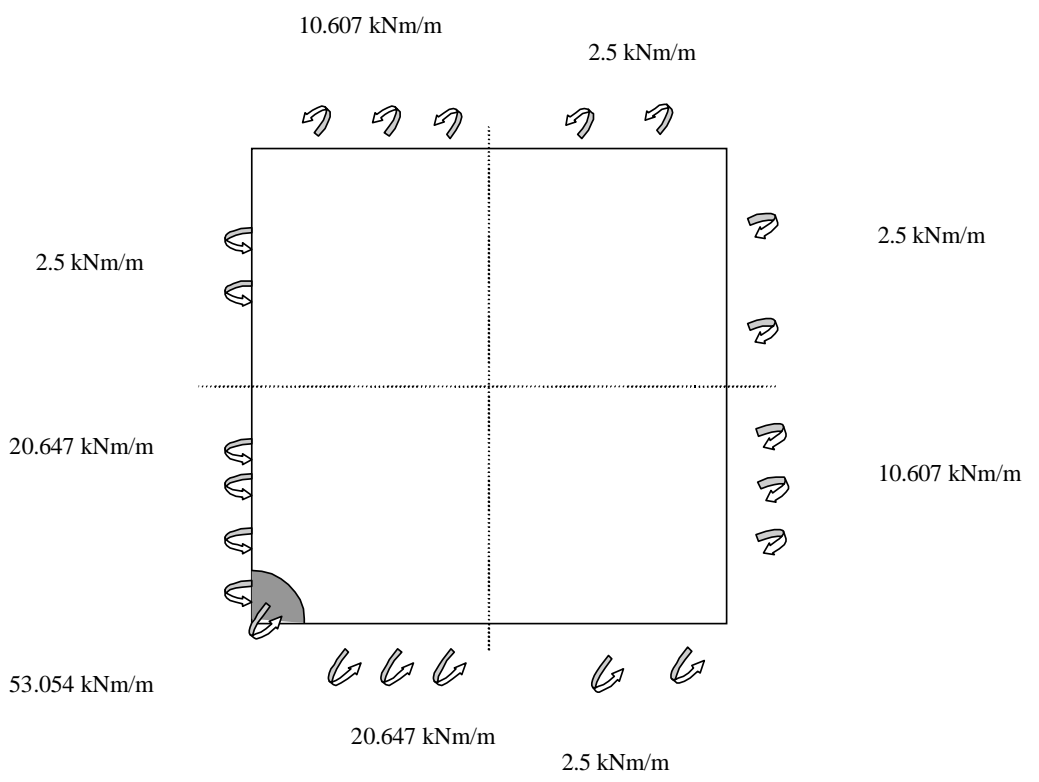

Fig. 3 Moment values calculated according to Saether's approach 


\subsection{Experiments on irregular flat slabs in the past to validate a design method}

To find a design procedure for flat slabs on irregular column layout two model slabs were designed and tested at NTU Singapore. Both seven-column [11] and fourteen-column [12] specimens were designed for an ultimate failure load of $10 \mathrm{kN} / \mathrm{m}^{2}$. The reinforcements were based on a preliminary design method [10]. Both specimens were $2 / 3$ scale models with $100 \mathrm{~mm}$ thickness. In the sevencolumn specimen the clear concrete cover measured before casting was $20 \mathrm{~mm}$ instead of $15 \mathrm{~mm}$ used in the design. Loading in both specimens was multiple point-loads simulating uniform load. Surprisingly, both specimens carried almost twice the design ultimate load. Critical values for crack width and deflections were reached only close to the design ultimate loads, confirming how conservative the adopted design approach was.

\section{EXPERIMENTAL STUDY}

Generally, in a slab design, in addition to the dead load a uniform imposed load is considered. However, applying this uniform load in a laboratory environment is challenging. Across a slab section, bending moments, shear forces, and twisting moments are present. If the calculations are based on strip theory then twisting moments can be assumed negligible. In the present experiments, with this assumption contra-flexure lines were selected as boundaries.

To apply uniform load a vacuum rig was constructed in the CUED Structures laboratory. The vacuum rig is a closed chamber with steel plates acting as bottom lid, aluminium ring beam as edges and clear polyethylene sheet as top cover (see Fig. 4). When the air inside the rig is sucked out by vacuum pumps the pressure inside the rig will drop. This creates a pressure difference across the specimen which acts as uniform load. To apply the shear forces, simply supported steel plates, supported on the slab edge on one end and on a wooden frame the other as shown in Fig. 4 were used.

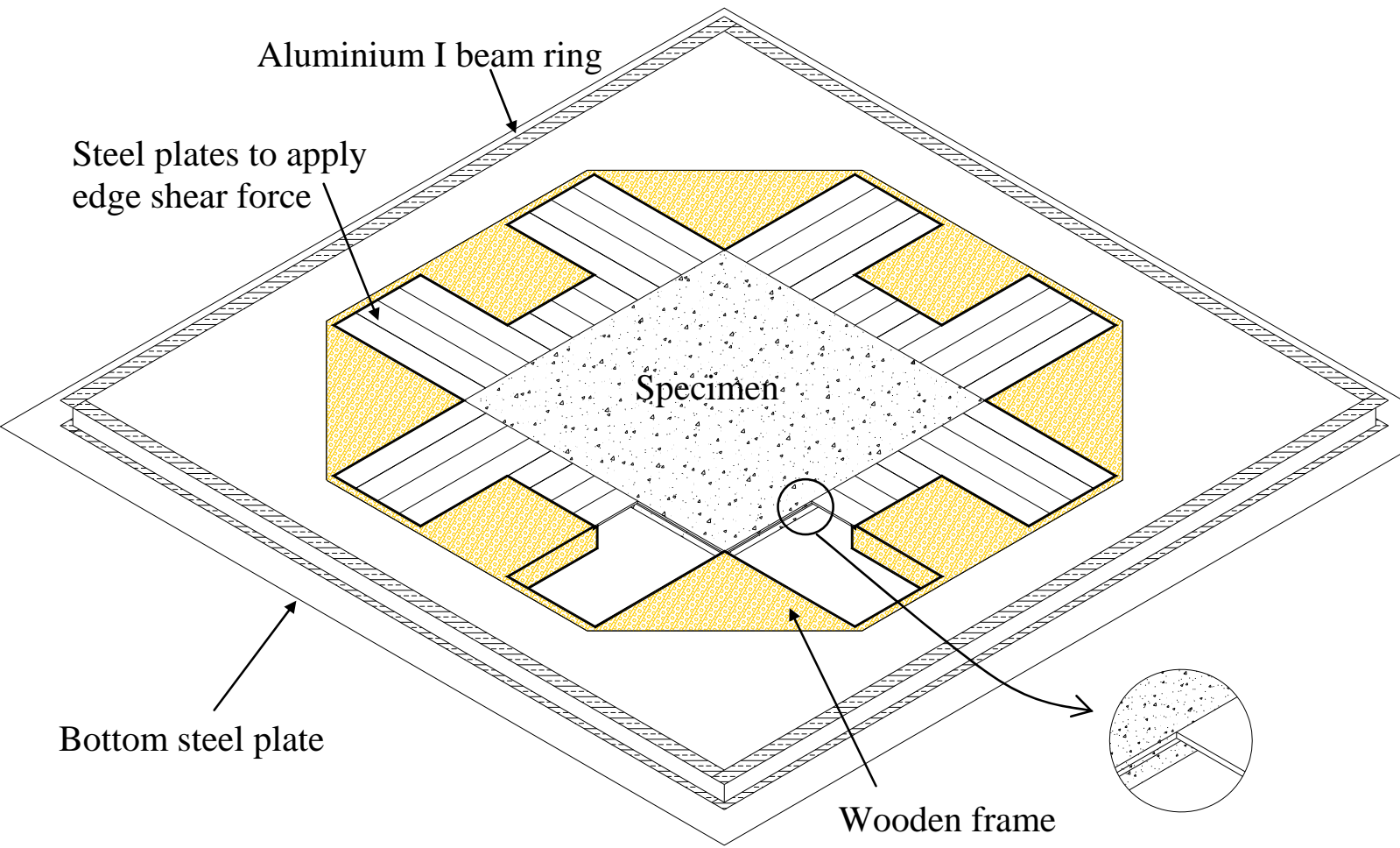

Fig. 4 Sketch of the experimental rig with part of the edge shear steel plates removed for clarity 
Edge restraints can increase the carrying capacity of slabs. Therefore $6 \mathrm{~mm}$ gaps were provided between the edge-shear steel plates and the slab edges. For the same reason edge shear steel plates were seated on a thin coat of silicone rubber and columns were mounted on roller bearings.

\subsection{Specimen details}

\subsubsection{Geometry \& reinforcement layout}

Instead of testing panels supported on completely irregular column layout as in NTU tests, a stepby-step approach was adopted. In the first series, four interior panel specimens supported on parallelogram column layout were tested. The second series had two interior panels of parallelogram layout and a corner panel of the same column layout. Reinforcement layouts for slab models 1-7 are shown in Fig. 5.

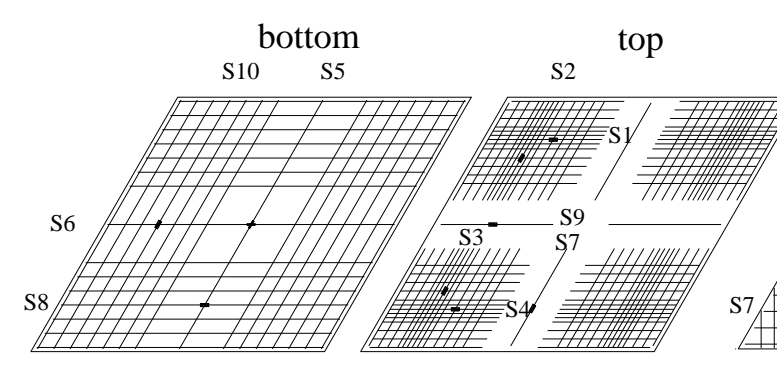

slab $1 \&$ slab 2

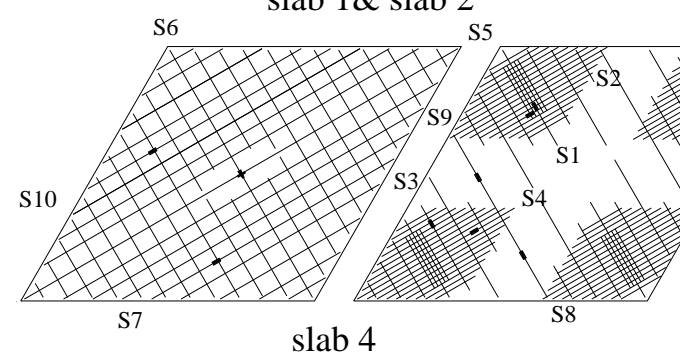

slab 4

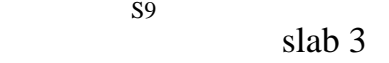

bottom

S5

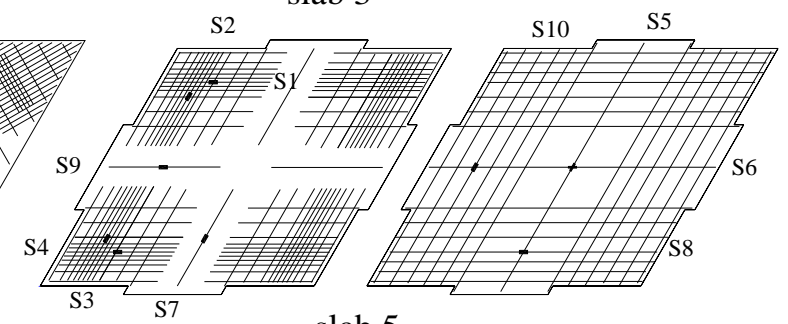

slab 5

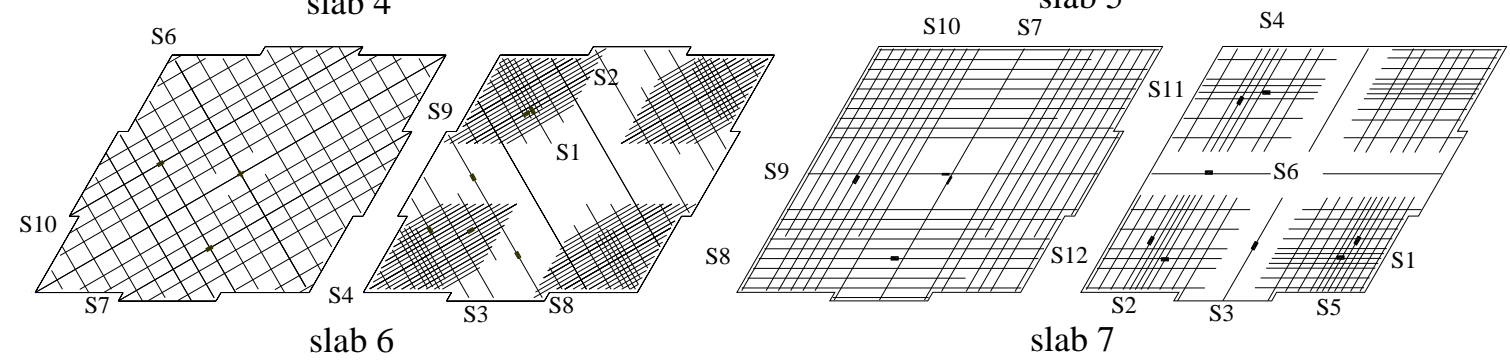

slab 6

slab 7

Fig. 5 Reinforcement layout for parallelogram slab specimens

Slab 8 was designed considering that the columns were in a triangular grid. However, applying the edge shear forces, following the strips in a triangular layout is difficult in an experiment. This is due to overlapping of edge shear steel plates of middle and column strips as shown in Fig. 6a. Therefore, although the design was based on columns in a triangular layout, edge shear forces applied were similar to that of parallelogram layout. Reinforcement layout of slab 8 was shown in Fig. 6b. Slabs 1-8 were supported on four columns each $120 \mathrm{~mm}$ square in cross section and $40 \mathrm{~mm}$ in height. Columns were non-reinforced and located at $1200 \mathrm{~mm}$ spacing. Details of slab 9 (had similar column layout to NTU-seven column specimen) are shown in Fig. 7. 


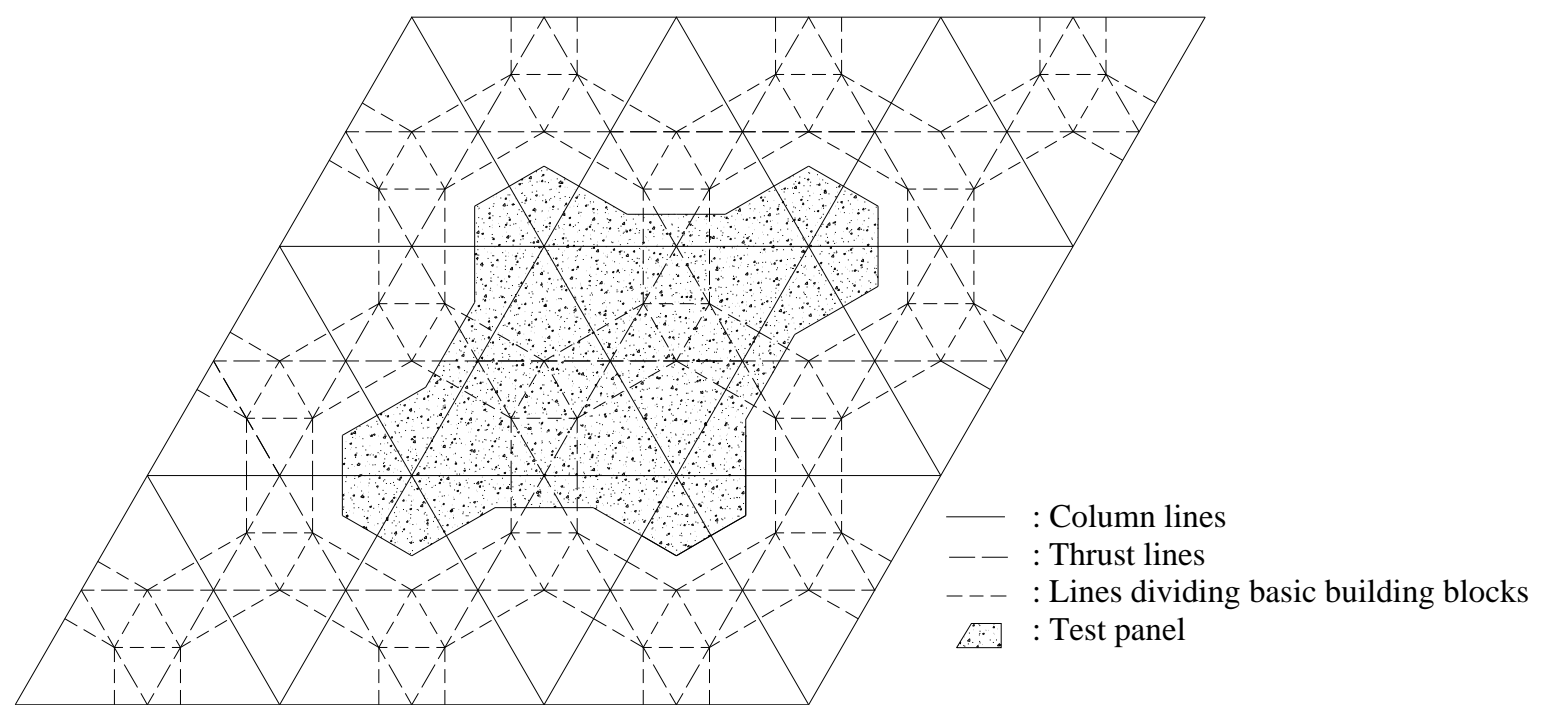

(a) Panel division according to Saether's method for triangular column grid.

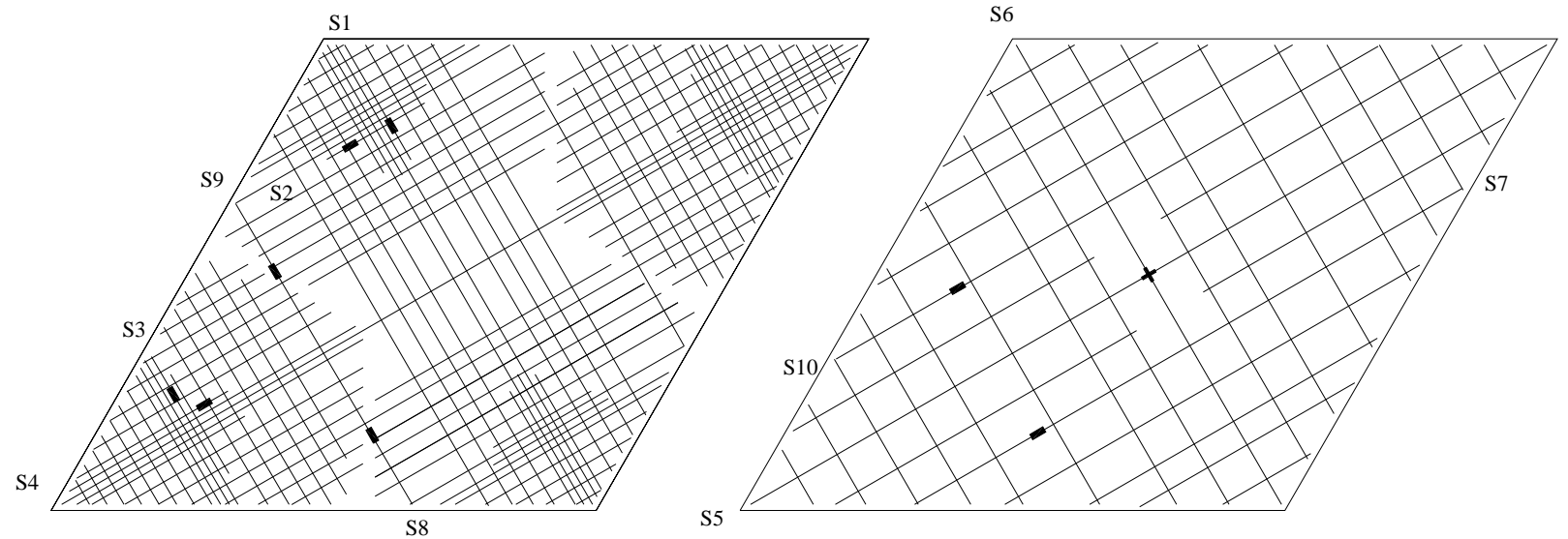

(b) Reinforcement layout for slab 8

Fig. 6 Details of slab 8 (specimen designed as supported on triangular column grid)

Moments in all specimens were calculated according to Saether's approach [2,3]. To change the reinforcement directions from that suggested by Saether, in slabs 3,4,6,8, and 9 Wood-Armer equations were used [13]. Code provisions for minimum or maximum steel were not strictly followed. However, an anchorage length equals to $150 \mathrm{~mm}$, found from a series of beam tests under flexure was provided for slabs 5,6,7,8 and slab 9. This development length in series one slabs was $100 \mathrm{~mm}$. One problem common in testing reduced scale models is avoiding punching shear failure. Punching shear reinforcement can contribute to flexural resistance and considerably affect the tests to validate a flexural design method. In the present experimental slabs (except for slab 1) spirals, with approximately $20 \mathrm{~mm}$ diameter and pitch made of $2.5 \mathrm{~mm}$ diameter wires were added in the column region to postpone punching. 


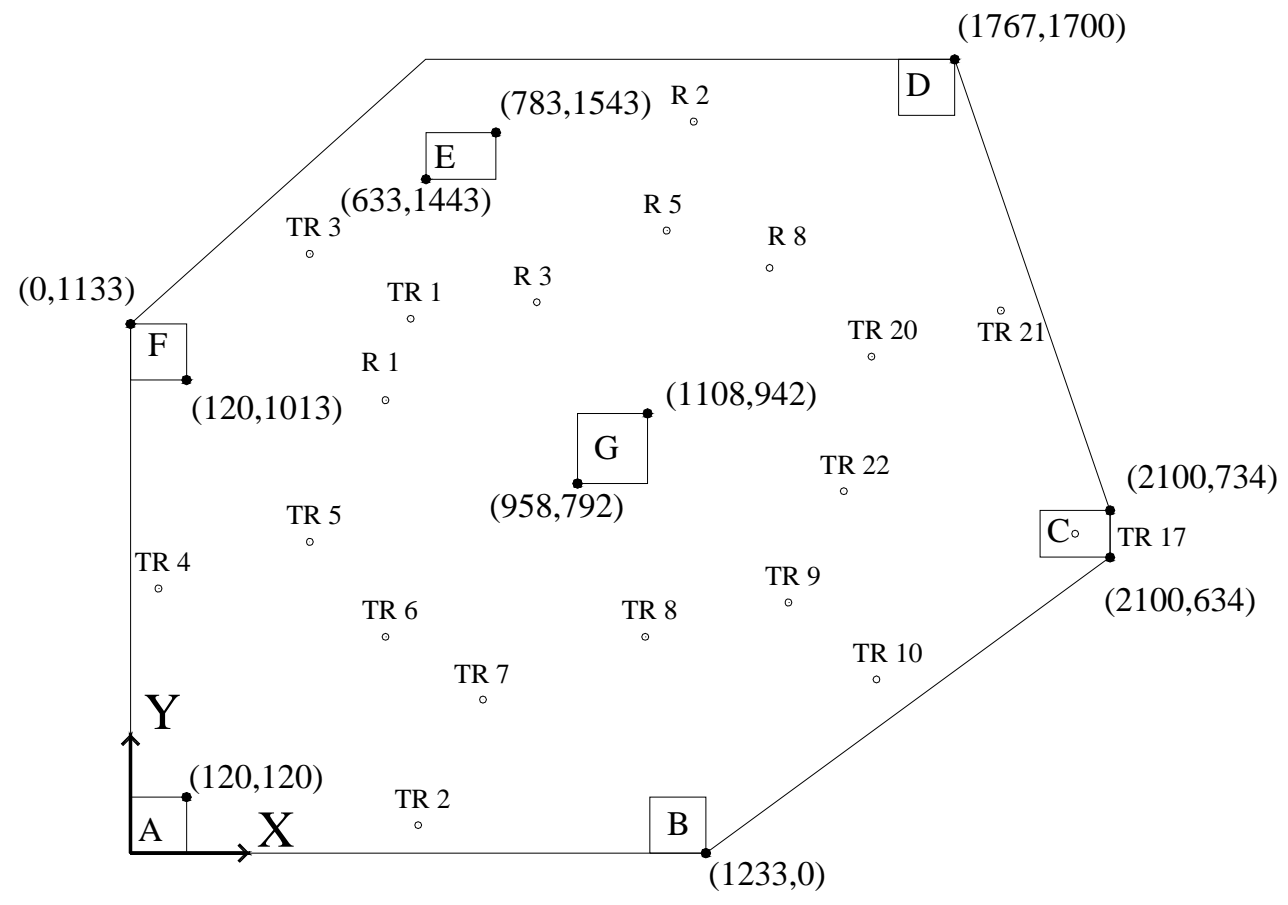

(a) Geometry (values in mm) and LVDT locations of CUED seven-column specimen

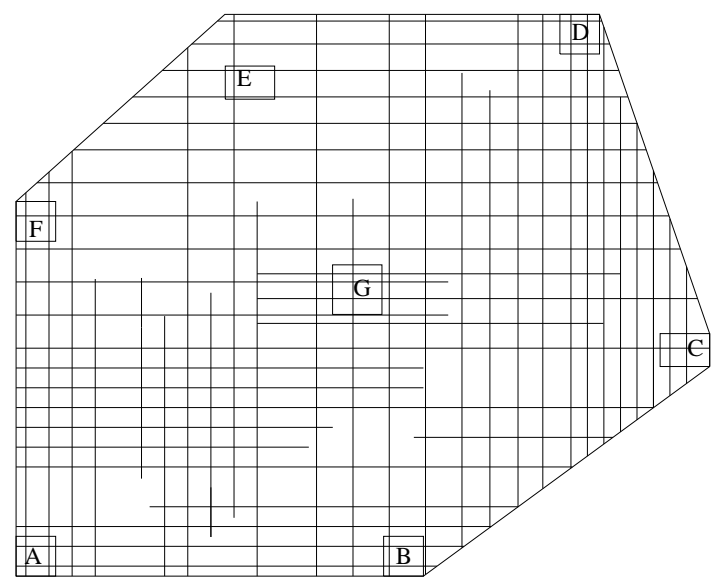

(i)

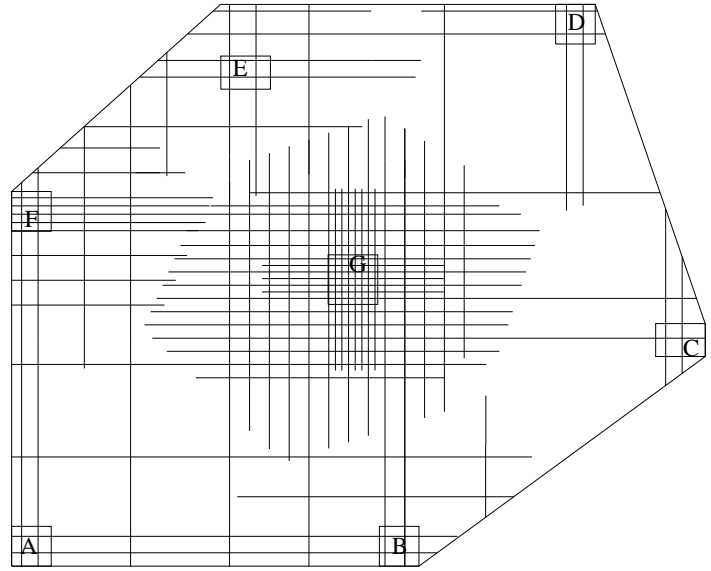

(ii)

(b) Reinforcement layouts for (i) bottom surface and (ii) top surface

Fig. 7 Details of CUED seven-column specimen

\subsubsection{Material}

The concrete mix used for all the specimens had water, ordinary Portland cement, fine aggregate and $6 \mathrm{~mm}$ single size aggregate in the ratios 0.5:1:2.35:2.87 respectively. Control specimens $(100 \mathrm{~mm}$ cubes and $100 \mathrm{~mm}$ diameter and $200 \mathrm{~mm}$ height cylinders) were cast from the same batch of concrete and tested on the same day. Strength values obtained from testing control specimens are tabulated in Table 2. Reinforcement used in all specimens was $4 \mathrm{~mm}$ diameter mild steel bars with yield strength $395 \mathrm{MPa}$. To improve the bond characteristics, the rebars were allowed to form rust on their surface before being used. 
Table 1 Details of experimental slabs supported on non-rectangular column layouts

\begin{tabular}{|c|c|c|c|c|c|c|c|c|c|}
\hline \multirow[t]{2}{*}{ Specimen } & \multirow[t]{2}{*}{$\begin{array}{l}\text { Thickness } \\
\text { (mm) }\end{array}$} & \multicolumn{2}{|c|}{$\begin{array}{c}\text { Clear concrete } \\
\text { cover } \\
(\mathrm{mm})\end{array}$} & \multirow[t]{2}{*}{$\begin{array}{l}\text { Age at test } \\
\text { (days) }\end{array}$} & \multicolumn{2}{|c|}{$\begin{array}{l}\text { Strength of concrete } \\
(\mathrm{MPa})\end{array}$} & \multirow[t]{2}{*}{$\begin{array}{c}\text { Design } \\
\text { ultimate } \\
\text { load } \\
(\mathrm{kPa})\end{array}$} & \multirow{2}{*}{$\begin{array}{l}\text { Exp. } \\
\text { failure } \\
\text { load } \\
(\mathrm{kPa})\end{array}$} & \multirow[t]{2}{*}{$\begin{array}{l}\text { Span / } \\
\text { rel. defl. }\end{array}$} \\
\hline & & $\stackrel{\circ}{\circ}$ & $\begin{array}{l}\text { E } \\
\stackrel{0}{0} \\
\text { D }\end{array}$ & & $\begin{array}{l}\text { Cube } \\
\text { strength }\end{array}$ & $\begin{array}{l}\text { Splitting } \\
\text { cylinder } \\
\text { strength }\end{array}$ & & & \\
\hline Slab 1 & 50 & 6 & 4 & 13 & 34 & 2.84 & 21.2 & 19.64 & 581 \\
\hline Slab 2 & 50 & 6 & 4 & 15 & 46.3 & 3.19 & 21.2 & 20.03 & $372^{*}$ \\
\hline Slab 3 & 50 & 6 & 6 & 21 & 39.8 & 3.10 & 21.2 & 19.54 & 238 \\
\hline Slab 4 & 50 & 6 & 6 & 18 & 51.3 & 3.22 & 21.2 & 18.92 & 211 \\
\hline Slab 5 & 60 & 8 & 8 & 15 & 51.5 & 3.18 & 25.0 & 25.31 & 351 \\
\hline Slab 6 & 60 & 8 & 8 & 15 & 54.4 & 3.52 & 25.0 & 24.9 & 984 \\
\hline Slab 7 & 60 & 8 & 8 & 21 & 48.1 & 3.4 & 25.0 & 23.81 & 351 \\
\hline Slab 8 & 50 & 6 & 6 & 20 & 54.7 & 3.87 & 21.2 & 20.43 & 408 \\
\hline Slab 9 & 50 & 6 & 6 & 13 & 45.2 & 3.47 & 20.0 & 25.86 & $456^{*}$ \\
\hline
\end{tabular}

Note: In slab 2, the central deflection gauge got jammed during the test between $12 \mathrm{kPa}$ and $15.4 \mathrm{kPa}$ total load and conservatively a linear variation is assumed. In slab 9 the value given is for panel ABGF.

\subsection{Experimental Results}

Figure 8 shows the locations of columns and displacement transducers in parallelogram slabs 1-8. In series one slabs, initial cracks formed were outside the panel $A B C D$, on top surface above acute corner columns $A$ and $C$. With further loading bottom surface cracks were observed via a mobile camera placed under the slabs. A short plateau in load deflection diagram was noticed with the opening of bottom surface cracks. This was followed by considerable increase in strain on bars along the central panel. For example strain gauges S5 in slab 1, S9 in slab 3, S6 in slab 4 and S6 in slab 6 reached strains well above yield strains (the label number of strain gauges are given at the end of the rebar on which that particular gauge was stuck in Fig. 5). Top surface cracks connecting column lines $\mathrm{AB}, \mathrm{BC}, \mathrm{CD}$ and $\mathrm{DA}$ formed between $14.2 \mathrm{kPa}$ and $15.4 \mathrm{kPa}$ in slab 1 and between $13.7 \mathrm{kPa}$ and $15.2 \mathrm{kPa}$ in slab 2. Column D punched in slab 1 after reaching $19.6 \mathrm{kPa}$ load at $36.6 \mathrm{~mm}$ central panel deflection (73\% of the slab thickness). However, in slab 2, test was stopped at $20 \mathrm{kPa}$ loading with $45 \mathrm{~mm}$ central deflection to avoid damage to the camera. Around $30 \mathrm{~mm}$ of residual deflection observed after complete unloading confirmed that the slab had deformed well into the plastic region. In slab 3, following the formation of bottom surface crack along diagonal $A C$ around $11.2 \mathrm{kPa}$, a diagonal crack along BD was seen on top surface at $12.5 \mathrm{kPa}$. In slab 3 , column A punched after reaching a maximum load of $19.5 \mathrm{kPa}$. See Table 3 for observed crack patterns. 


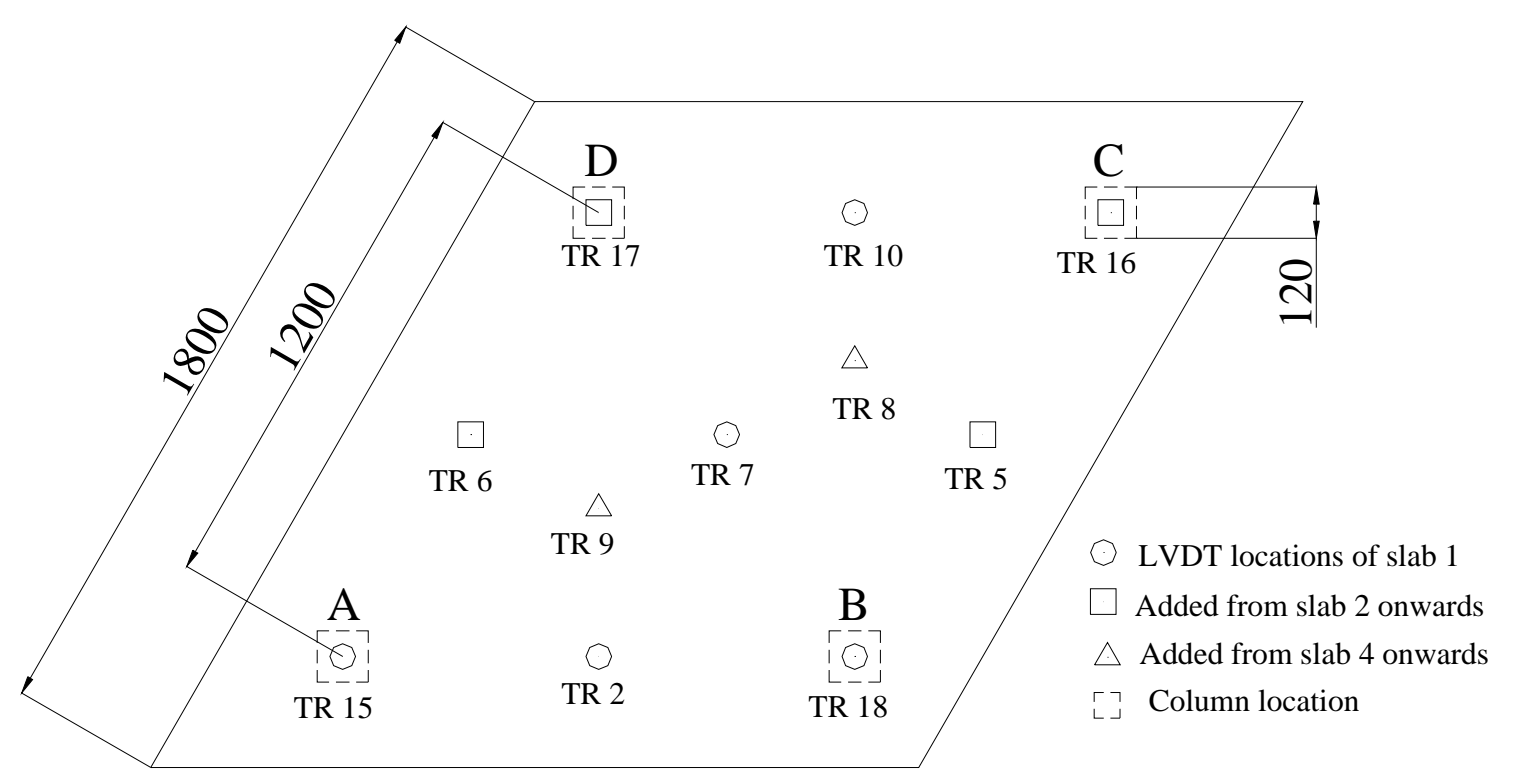

Fig. 8 Few common details of parallelogram slab specimens

In slab 5, initial cracks formed on bottom surface along diagonal AC around $13.4 \mathrm{kPa}$. In contrast to previous slabs, top surface cracks above acute corner columns were seen only at $20.3 \mathrm{kPa}$. After forming cracks along column lines, slab 5 failed by snapping of reinforcement across the mid span at $25.3 \mathrm{kPa}$. The failure pattern was a valley. In the corner panel, first cracks were seen above column $\mathrm{B}$, which is the interior column in the corner panel. Strain gauges S1 and S5 stuck on top steel reached yield strains around $18.9 \mathrm{kPa}$ and $20 \mathrm{kPa}$. With further loading cracks along column lines $\mathrm{AB}, \mathrm{BC}$ formed at 22kPa. By that load, strain gauges S1, S5, S7, S10, S8 and S3 had already reached yield strains. Finally slab 7 failed by punching of column B with the central deflection $31 \mathrm{~mm}$.

In the slab 8, first cracking occurred outside the acute corner columns around $9.5 \mathrm{kPa}$. Flexural cracks inside the panel on top surface were seen at $12.5 \mathrm{kPa}$ close to column $\mathrm{A}$, and along column lines $\mathrm{BC}$ and $\mathrm{BD}$ around $14.8 \mathrm{kPa}$ and $15.9 \mathrm{kPa}$ respectively. Final failure was by punching of column $B$ after reaching maximum load $20.4 \mathrm{kPa}$ at a maximum central deflection $31.5 \mathrm{~mm}$. In the CUED seven-column specimen first cracks were seen above column $\mathrm{G}$ around $14.8 \mathrm{kPa}$. Cracks along column line BG, and above column $\mathrm{F}$ appeared at $16.5 \mathrm{kPa}$. With further loading top surface cracks along column lines EG and FG formed between $18 \mathrm{kPa}$ and $19 \mathrm{kPa}$. After reaching the peak load 25.9 $\mathrm{kPa}$, rotation about column $\mathrm{C}$ increased dramatically and bottom bars in the panel BCDG failed in fracture. 
Morley Symposium on Concrete Plasticity and its Application. University of Cambridge $23^{\text {rd }}$ July, 2007

Table 2 Observed crack patterns in experimental slabs

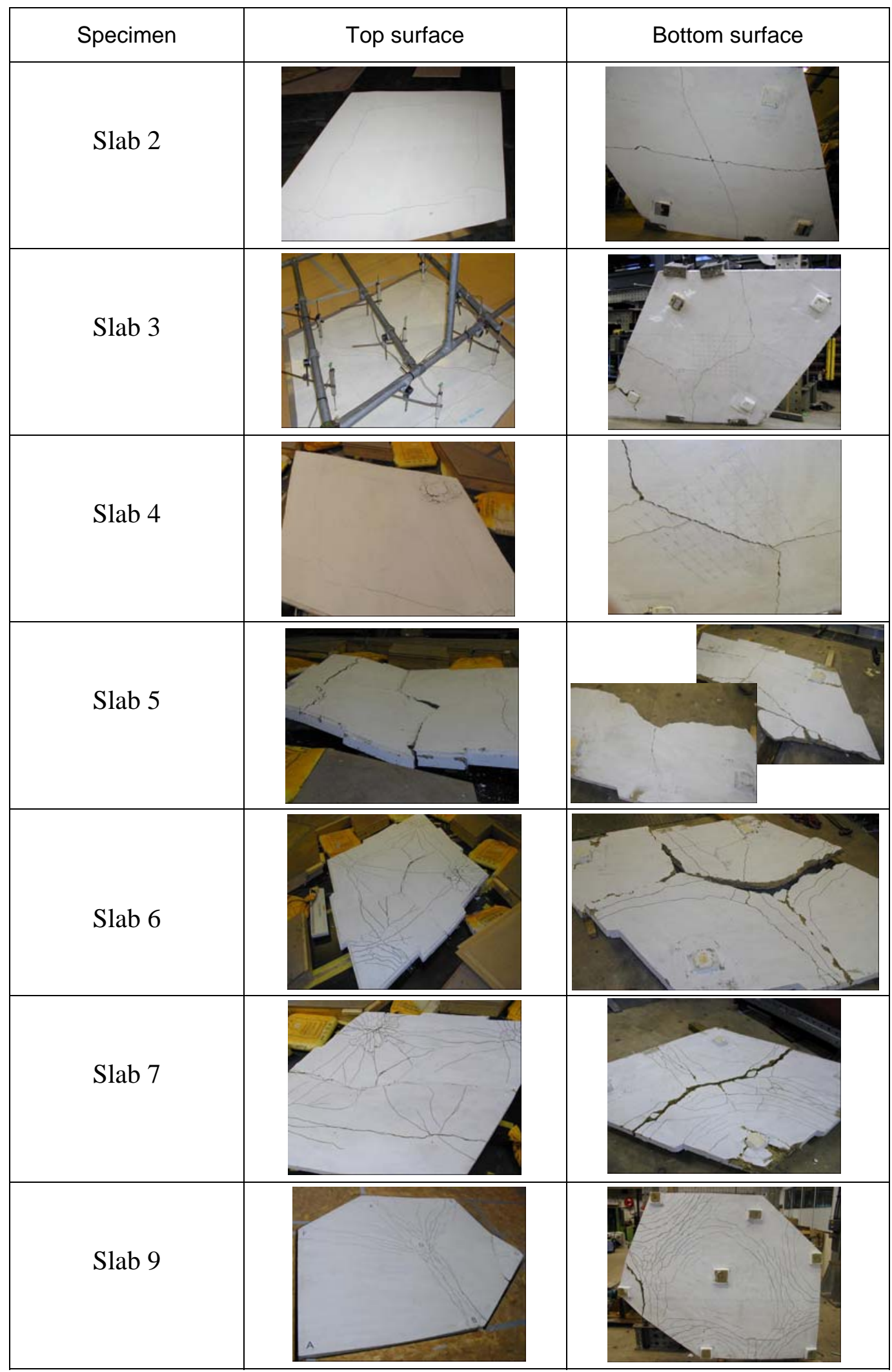




\subsection{Observations and Discussions}

To satisfy the design performance requirements, flat slabs must be within the ultimate and serviceability limit states, under respective load values. In this section behaviour of the experimental slabs is considered at both limit states.

\subsubsection{Behaviour at service load}

Excessive deflection and wide cracks are common problems at service load. To calculate the service load from the ultimate design load, load factors 1.4 and 1.6 were used for dead and imposed loads respectively. The span over deflection ratios were calculated based on relative deflection values (relative deflection $=$ measured deflection - average deflection above columns) and tabulated in Table 2. Considering possible creep deformations, slabs designed according to Saether may have problem at service load. For example slabs 3 and 4 don't satisfy the requirements of BS 8110 .

In Fig. 9 central deflection and strain gauge readings of slab 4 are plotted together against the applied imposed load. Around $11 \mathrm{kPa}$ imposed load (i.e. 12.2kPa total load) while applied load was remaining almost constant, central deflection doubled $(2 \mathrm{~mm}$ to $4.4 \mathrm{~mm}$ ) and strain gauges stuck on bottom steel S6, S7 and S10 showed rapid increase in strains. Although similar behaviour was observed in slab 6 (bottom reinforcement layout was similar to that of slab 4 except for 2 bars were continuous in slab 6), the plateau in the deflection diagram was short. The fact is the bottom reinforcement provided in the mid span is lower than the code minimum to avoid immediate yielding of steel with cracking. The mid span bottom steel ratio in slab 4 is $0.08 \%$ and that in slab 6 is $0.1 \%$ (both are lower than the BS 8110 recommended minimum).

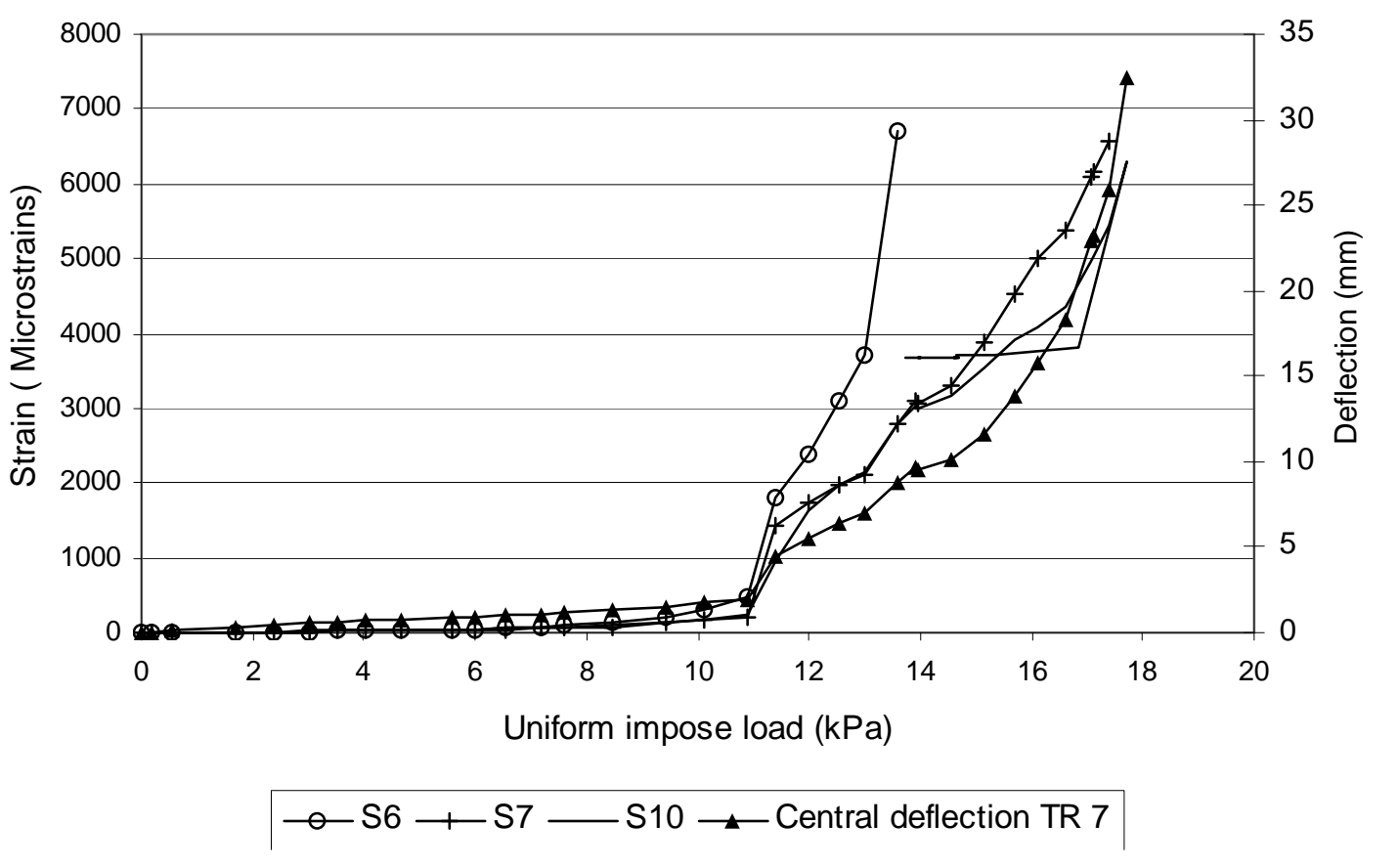

Fig. 9 Load vs. strain gauge readings and central deflection measured in slab 4

\subsubsection{Behaviour at ultimate load}

A flat slab can fail by columns punching through the slab, crushing of concrete or rupture of rebar. If these failures occur after considerable warning then any preventive measures can be implemented to avoid disaster. Also a good design method must predict the failure load close enough (more reliable). Considering the deflections at which final failure occurred in the experimental slabs, Saether's method satisfies the warning requirements. However, the actual failure loads are slightly less than the prediction. Some of the possible causes may be bottom steel in the mid span region is 
unloading after yielding, selection of boundary location, and neglecting twisting moments. By providing minimum steel in the mid panel region the deflection behaviour at service load can be improved. This will also increase the ultimate failure load.

\section{CONCLUSIONS}

Proportioning of steel according to Saether's method seems to predict the failure load well. However, for the loads considered, the reinforcement ratios in mid span are below the code specified minimum and resulted in yielding of steel with the formation of bottom surface cracks. It is recommended to provide code specified minimum steel at these locations.

The bimoment method, applied to slabs with twisting moments, revealed some important relationships between difference in calculated bimoments and the work done by the twisting moments inside the panel (considering hyperbolic paraboloid shaped virtual displacement field). If brought together, this approach and Wood-Armer equations can reduce the uncertainty in design methods based on strips for beamless slabs.

\section{REFERENCES}

[1] Wiesinger, F.P., "Design of flat slabs with irregular column layout", ACl journal, February 1973, vol. 70, pp117-123.

[2] Saether, K., "Flat plates with regular and irregular column layouts. I: analysis", Journal of structural Engineering, May 1994, 120(5), pp 1563-1579.

[3] Saether, K., "Flat plates with regular and irregular column layouts. II: numerical evaluations", Journal of structural Engineering, May 1994, 120(5), pp 1580-1598.

[4] Gurley, C. R., "Bi-moment equilibrium of finite segments of Hillerborg plate", Magazine of Concrete Research, September 1979, vol. 31, No. 108, pp 142-150.

[5] Van Buren, M.P., "Staggered columns in flat plates", Proceedings of the American Society of Civil Engineers, June 1971, vol. 97, No. ST6, pp 1791-1797.

[6] Hillerborg, A., Strip method of design, Cement and Concrete Association. Wexham Springs, London, 1975, pp 120-219.

[7] Wood, R. H. and Armer, G. S. T, "The theory of strip method for design of slabs", Proceedings of the Institution of Civil Engineers, October 1968, vol. 41, No. 10, pp 285-311.

[8] Kemp, K.O. A, "strip method of slab design with concentrated loads or supports", The Structural Engineer, December 1971, vol. 49, no 12, pp 543-548.

[9] Hillerborg, A., Strip method design handbook, E \& FN Spon publication, First edition, 1996.

[10] Tan H. N. and Teng S., "Test of a 7-column irregular flat-plate floor", Research report, phase 2A, Nanyang Technological University - Singapore, August 2000.

[11] Jianzeng, G., Teng, S. and Kiat, C. H., "Test of a 14-column irregular flat-plate floor", Research report, phase 2B, Nanyang Technological University - Singapore, August 2000.

[12] Teng, S., Tan H. N., Irawan P. and Kiat, C. H., "Test of a 7-column irregular flat-plate floor" Seminar on flat plate for residential projects, NTU-Singapore, September 2000.

[13] Wood, R. H., "The reinforcement of slabs in accordance with a predetermined field of moments", Concrete, February 1968, pp. 69-76.

[14] Morley, C.T., Kemp K.O., Lowe P.G. and Gurley C. R., Discussion on Bi-moment equilibrium of finite segments of Hillerborg plate. Magazine of concrete research, September 1980, vol.32, no 112, pp 176-185.

[15] Wood, R. H., Plastic and elastic design of slabs and plates, Thames and Hudson, London, 1961. 
Morley Symposium on Concrete Plasticity and its Application. University of Cambridge $23^{\text {rd July, } 2007}$ 